\title{
Differential Effects of Phenylalanine Ammonia Lyase, Cinnamyl Alcohol Dehydrogenase, and Energetic Metabolism Inhibition on Resistance of Appropriate Host and Nonhost Cereal-Rust Interactions
}

\author{
E. Prats, F. Martínez, M. M. Rojas-Molina, and D. Rubiales
}

First, third, and fourth authors: CSIC, Institute of Sustainable Agriculture, Apdo. 4084, E-14080 Córdoba, Spain; and second author: Departamento de Ingeniería Agroforestal, Universidad de Sevilla, Carretera de Utrera km1, Sevilla, Spain. Accepted for publication 26 July 2007.

\begin{abstract}
Prats, E., Martínez, F., Rojas-Molina, M. M., and Rubiales, D. 2007. Differential effects of phenylalanine ammonia lyase, cinnamyl alcohol dehydrogenase, and energetic metabolism inhibition on resistance of appropriate host and nonhost cereal-rust interactions. Phytopathology 97:1578-1583.

Effects of phenylpropanoid and energetic metabolism inhibition on resistance were studied during appropriate host and nonhost cereal-rust interactions. In the appropriate barley-Puccinia hordei interaction, phenylalanine ammonia lyase (PAL) and cinnamyl alcohol dehydrogenase (CAD) inhibition reduced penetration resistance in two genotypes, suggesting a role for phenolics and lignins in resistance. Interestingly, penetration resistance of the barley genotype 17.5.16 was not affected by

phenylpropanoid biosynthesis but penetration resistance was almost completely inhibited by D-mannose, which reduces the energy available in plant host cells. This suggests a parallel in the cellular basis of penetration resistance between 17.5.16 rust and mlo barleys powdery mildew interaction. Results revealed differing patterns of programmed cell death (PCD) in appropriate versus nonhost rust interactions. PAL and CAD inhibitors reduced PCD (hypersensitivity) in appropriate interactions. Conversely, they had no effect in PCD of wheat to P. hordei; whereas Dmannose dramatically reduced nonhost resistance and allowed colony establishment. The differential effects of inhibitors in the expression of the different resistances and the commonalities with the cereal-powdery mildew interaction is analyzed and discussed.
\end{abstract}

Puccinia hordei Otth. is a biotrophic fungal pathogen that causes leaf rust of barley (Hordeum vulgare L.), which is a worldwide problem. The fungus enters the host leaf through stomata to form intercellular hyphae that differentiates haustorial mother cells (HMCs) upon contact with a host cell surface within the lamina. A penetration peg then attempts to penetrate host mesophyll cells and form an intracellular nutrient-absorbing haustorium (29). Attempted penetration may trigger different host cell defense responses that can act as both prepenetration to prevent haustorium formation or postpenetration to arrest further fungal development.

Penetration resistance is associated with papillae, apoplastic cell wall appositions deposited by host cells, which act as physical or chemical barriers to attempted penetration $(36,42)$. Papillae have been extensively studied in the cereal-powdery mildew, Blumeria graminis DC (Speer), interaction (reviewed by Zeyen et al. [42]). In cereal epidermal cells, penetration resistance is strongly associated with the accumulation of autofluorogenic phenolic compounds in papillae. These autofluorogens are products of the phenylpropanoid biosynthesis activated de novo in response to fungal attack (6). Inhibition of either phenylalanine ammonia lyase (PAL, the gateway enzyme to phenylpropanoid biosynthesis) or cinnamyl alcohol dehydrogenase (CAD, necessary for the lignin biosynthesis) markedly suppressed papilla autofluorescence and increased fungal penetration success $(4,6)$. By contrast, PAL inhibition had no detectable effect on the penetration resistance of barley attacked by inappropriate $B$. graminis (f. spp. avenae and tritici). This suggested that factors other than

Corresponding author: E. Prats; E-mail address: bb2prpee@uco.es

doi:10.1094/PHYTO-97-12-1578

(c) 2007 The American Phytopathological Society phenolic compounds are of major significance in determining the effectiveness of inappropriate host penetration resistance to barley powdery mildew (5). Nevertheless, the dependence of inappropriate host penetration resistance on the energy-demanding plant cell activity level was clearly evidenced by dramatic suppression in leaves treated with the phosphate scavengers deoxy-D-glucose (DDG) or D-mannose (43).

If penetration resistance fails, a second defense mechanism involving race-specific, programmed cell death (PCD-hypersensitivity) (10) may be triggered to arrest pathogen growth. Such PCD has been described in many pathosystems including the cereal rusts $(14,26,28,39)$. PCD may also occur during nonhost interactions, but evidence suggests processes leading to PCD differ between $R$-gene controlled and nonhost interactions (7). Thus, inhibition of phenylpropanoid biosynthesis strongly suppressed race-specific PCD conditioned by the Mla1 allele in barley (41). By contrast, such inhibition had relatively little or no effect on frequency of PCD in barley attacked by inappropriate $B$. graminis f. spp. (5). Nevertheless, application of DDG strongly suppressed nonhost cell death, possibly through repressing plant gene transcription rather than phosphate scavenging since D-mannose had little effect on this form of PCD (43).

In relation to rust fungi, some attention has been paid to the chemical constitution of papillae in relation to penetration resistance $(35,36)$. It has been reported that callose accumulation in papillae increases resistance to various rust fungi of wheat (including $P$. graminis f. sp. tritici, $P$. triticina, and $P$. striiformis; $12,14,39)$ and barley $(25)$. However, no work was done to define the role of phenolic compounds in papillae. The role of autofluorogenic compounds in cell death has received some attention and the available information indicates their accumulation during both $R$-controlled PCD and nonhost PCD. For example, synthesis of phenolic compounds was associated with mesophyll PCD in 
wheat following a race-specific interaction due to attack by avirulent isolates of $P$. recondita and $P$. graminis f. sp. tritici (37-39). This was also true of nonhost PCD following attack by the oat crown rust fungus, $P$. coronata f. sp. avenae (22). Similarly, in cowpea, nonpathogenic rust fungi elicited PAL activity and caused autofluorescence associated with cell death (8), while virulent pathogens caused no such effects.

The current study was designed to determine the cellular bases of resistance to $P$. hordei in its barley host and in wheat, a nonhost species. To explore the energy level requirement for expression of resistances, D-mannose was applied to disrupt energy metabolism through its action as a plant cell phosphate scavenger that has low fungitoxicity (43). To examine the importance of phenylpropanoid synthesis in execution of defenses, we applied $\alpha$ aminooxy- $\beta$-phenylpropionic acid (AOPP), a competitive PAL inhibitor (2) and ([\{(2-hydroxyphenyl) amino $\}$ sulphinyl $]$ acetic acid, 1.1 dimethyl ester) (OH-PAS), a specific CAD inhibitor (6), thus interfering with an essential precursor to lignin biosynthesis. These approaches were aimed for further understanding the differences or commonalities in plant processes engaged during expression of different forms of resistance to $P$. hordei.

\section{MATERIALS AND METHODS}

Pathogen and plant material. $P$. horde $i$ isolate 1.2.1. (avr1, 2, $4,6,8,12 / \operatorname{Avr} 3,5,7,9)$ was used. Urediniospores were multiplied on plants of L94, which was highly susceptible. One day before experimental inoculation, spores were collected and kept overnight in a desiccator.

Barley line L94 was also used as the susceptible barley genotype for experimentation. As examples of genotypes with racespecific PCD resistance, we used its near isogenic derivative L94+Rph7 (with gene Rph7) and cv. Ribari (with gene Rph3). Cv. Vada and barley line 17.5.16 were selected as genotypes with high levels of partial resistance that are not PCD dependent $(19,20)$. Wheat cv. Little Club was used as a nonhost to barley leaf rust. Seedlings were grown in 1-liter pots filled with peat/sand (3:1) in a growth chamber at $20^{\circ} \mathrm{C}, 65 \%$ relative humidity $(\mathrm{RH})$, and 12 -h dark/12-h light with $150 \mu \mathrm{mol} \cdot \mathrm{m}^{-2} \cdot \mathrm{s}^{-1}$ photon flux density supplied by high-output white fluorescent tubes. All experiments used fully expanded first-formed leaves of 11-day-old plants (their second-formed leaf was unrolling).

Chemicals treatments. D-Mannose (Sigma-Aldrich Co. Ltd, St. Louis, MO) and the PAL inhibitor, AOPP, (Genosys Biotechnologies Ltd., Pampisford, U.K.) were dissolved in distilled water to give $10 \mathrm{mM}$ and $1 \mathrm{mM}$ solutions, respectively. Distilled water was used as a control in both cases. The CAD inhibitor, OH-PAS, synthesized by D. A Boyles $(3,6)$ is moderately water insoluble. To obtain a concentration of $1 \mathrm{mM}$, the appropriate amount of $\mathrm{OH}-\mathrm{PAS}$ was dissolved in $100 \mathrm{ml}$ of distilled water containing 20 drops of $0.1 \mathrm{NaOH}$, with continuous stirring for approximately $3 \mathrm{~h}$. Distilled water containing the same amount of $\mathrm{NaOH}$ was used as a control.

Application of the inhibitors, inoculation, and incubation. For mannose treatment, prior to inoculation, leaves were cut and the abaxial epidermis was stripped from the central region of leaf blades to expose the mesophyll. Excised stripped leaves were floated so that the exposed leaf mesophyll was bathed in Dmannose solution or on water (controls) in $10-\mathrm{cm}^{2}$ petri dishes. The intact adaxial surface remained dry and was not in contact with the solutions. This procedure allows efficient leaf uptake of D-mannose by the leaves (17). Twenty four hours after incubation, four leaves of each genotype/treatment combination were inoculated. Urediniospores mixed in talc $(1: 20 \mathrm{v} / \mathrm{v})$ were dusted over the excised leaves to give approximately 200 spores $\mathrm{cm}^{-2}$ (checked by counts made from glass slides laid adjacent to leaves). After inoculation, excised leaves were incubated for $9.5 \mathrm{~h}$ in darkness at $100 \% \mathrm{RH}$ and $18^{\circ} \mathrm{C}$, and thereafter, at $20^{\circ} \mathrm{C}$ under a 14-h photoperiod with $150 \mu \mathrm{mol} \cdot \mathrm{m}^{-2} \cdot \mathrm{sec}^{-1}$ photon flux density. After $48 \mathrm{~h}$, the D-mannose solution was replaced by water to avoid possible stress because of prolonged uptake of D-mannose. Excised leaves were fixed 3.5 days after inoculation with viable $P$. hordei isolate 1.2.1 urediniospores.

For AOPP and OH-PAS treatments, leaves were excised at the soil level. The second-formed leaf was excised and the cut end of the first was submerged in water, trimmed to remove air embolisms, and then immersed in either PAL or CAD inhibitor or their respective controls. Leaves were incubated for $24 \mathrm{~h}$ in a growth chamber at $20^{\circ} \mathrm{C}$ under a 12 -h photoperiod and $150 \mu \mathrm{mol} \cdot \mathrm{m}^{-2} \cdot \mathrm{s}^{-1}$, allowing leaves to uptake the test solution. To prevent wilting and allow test solution uptake, cut leaf ends were trimmed twice during the incubation. After $24 \mathrm{~h}$, leaves were removed from test solutions, inoculated, and immediately returned to test solutions (see above). After $48 \mathrm{~h}$, all solutions were replaced by water to avoid possible stress because of prolonged uptake of PAL or CAD inhibitor and leaves were fixed 3.5 days after inoculation.

Microscopic observations. After incubation, 2-cm leaf segments of each leaf were prepared for microscopy according to Niks and Rubiales (28). Leaf segments were observed with UV light incident fluorescent microscopy $(330 \mathrm{~nm}$ excitation/380 nm emission) with a Leica DM LS phase contrast microscope (Leica Microsystems, Wetzlar, Germany; 100× objective). On each leaf segment, 100 infection units (growth arising from individual spores) that successfully formed an appressorium on a stoma were scored and classified according to their developmental stage (24). Accordingly, early-aborted $P$. hordei infection attempts because of penetration resistance were those that formed a substomatal vesicle and one or more primary infection hyphae but forming less than six HMCs and where colony growth had ceased. Infection units with six or more HMCs were considered established. The length (L) and width (W) of established colonies was measured by eyepiece graticule, and colony size (CS) was calculated by the formula: $\mathrm{CS}=1 / 4 \pi L W$ (in which $L=$ maximum length and $W=$ maximum width of a colony). Values for areas were transformed to square roots to obtain a linear value for colony area (25). PCD, as a result of $P$. hordei attack, was recognized by yellow wholecell fluorescence under violet incident light (420 nm excitation/490 nm emission).

Four leaves (from four different plants) per genotype and treatment were studied in a completely randomized block design. Data recorded as percentages were transformed to arcsine square roots (transformed value $=180 / \pi \times \operatorname{arcsine}[\sqrt{ }(\% / 100)]$ ) to normalize data and stabilize variances throughout the data range and subject to analysis of variance using GenStat 7th Edition, after which residual plots were inspected to confirm data conformed to normality.

\section{RESULTS}

Tables 1-3 show data from observations made at the stages of development reached by $P$. hordei germlings 3.5 days after inoculation of the various barley genotypes and wheat cv. Little Club. Data from histological analysis of differing genotypes agreed with previous studies $(19,20)$. Control values differed between experiments (Tables 1-3), but the behavior of the barley genotypes to rust infection was consistent. Thus, genotype L94 was highly susceptible. It had a high percentage of established colonies that did not incite cell death. This would explain the large colony size observed in L94 (approximately $0.4 \mathrm{~mm}^{2}$ ). In barley genotype Vada and genotype 17.5.16, known to express partial resistance, early fungal colony abortion in the absence of whole mesophyll cell autofluorescence was presumably because many HMCs failed to penetrate mesophyll cells. By contrast, the two genotypes with major $R$ genes ( $R p h 7$ and $R p h 3$ ) had dead mesophyll cells due to PCD. However, in cv. Ribari, reduced colony size was observed when compared with L94, whereas in L94+Rph7, the colonies had a lar- 
ger size than did those in Ribari. The nonhost interaction showed the highest levels of PCD. This happened very early in attempted infection since colonies hardly reached $0.05 \mathrm{~mm}^{2}$ (Tables $1-3$ ).

Inhibition of PAL and CAD by treatment with AOPP and $\mathrm{OH}-$ PAS, respectively, abolished the penetration resistance of Vada and allowed establishment of colonies whose size was similar to the susceptible control L94. Thus, percentage of established colonies increased approximately 50\% and colony size increased approximately $0.2 \mathrm{~mm}^{2}$ (Tables 1 and 2). Penetration resistance of 17.5.16 was not affected by AOPP treatment, although it reduced

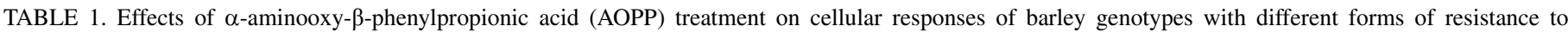
Puccinia hordei and in a nonhost interaction with wheat (cv. Little Club) at 3.5 days postinoculation ${ }^{\mathrm{a}}$

\begin{tabular}{|c|c|c|c|c|c|}
\hline Genotype & Treatment & $\begin{array}{l}\text { Penetration resistance }(\%) \\
\text { (EA colonies) }\end{array}$ & $\begin{array}{l}\text { Established colonies } \\
\text { with dead cells }(\%)\end{array}$ & $\begin{array}{c}\text { Established colonies } \\
\text { without dead cells }(\%)\end{array}$ & $\begin{array}{l}\text { Colony size } \\
\left(\mathrm{mm}^{2} \times 10^{-2}\right)\end{array}$ \\
\hline \multirow[t]{2}{*}{ L94 } & Control & $7.0 \pm 1.0$ & $7.0 \pm 3.06$ & $86.0 \pm 3.51$ & $43.9 \pm 2.91$ \\
\hline & AOPP & $9.7 \pm 4.18$ & $0.7 \pm 0.67$ & $89.6 \pm 3.93$ & $49.2 \pm 2.98$ \\
\hline \multirow[t]{2}{*}{ Vada } & Control & $50.6 \pm 1.49$ & $3.6 \pm 0.96$ & $45.8 \pm 1.93$ & $18.6 \pm 0.60$ \\
\hline & AOPP & $9.0 \pm 1.58 * \mathrm{~b}$ & $4.3 \pm 0.85$ & $86.7 \pm 2.39^{*}$ & $38.5 \pm 1.23 *$ \\
\hline \multirow[t]{2}{*}{ 17.5.16 } & Control & $57.5 \pm 4.57$ & $11.3 \pm 3.09$ & $31.2 \pm 6.06$ & $15.0 \pm 0.66$ \\
\hline & AOPP & $51.8 \pm 3.22$ & $1.8 \pm 0.48^{*}$ & $46.4 \pm 3.21 *$ & $18.9 \pm 1.20 *$ \\
\hline \multirow[t]{2}{*}{ Ribari (Rph3) } & Control & $14.3 \pm 1.49$ & $16.3 \pm 1.49$ & $69.4 \pm 2.25$ & $31.6 \pm 2.09$ \\
\hline & AOPP & $2.3 \pm 1.31^{*}$ & $0.5 \pm 0.25^{*}$ & $97.2 \pm 1.38 *$ & $48.2 \pm 0.97 *$ \\
\hline \multirow[t]{2}{*}{ L94+Rph7 } & Control & $16.3 \pm 4.64$ & $64.3 \pm 7.16$ & $19.4 \pm 2.60$ & $33.5 \pm 2.45$ \\
\hline & AOPP & $11.5 \pm 0.50$ & $67.8 \pm 6.98$ & $20.7 \pm 6.60$ & $37.0 \pm 1.39$ \\
\hline \multirow[t]{2}{*}{ Little Club } & Control & $5.9 \pm 0.34$ & $94.1 \pm 0.34$ & $0.0 \pm 0.0$ & $1.0 \pm 0.52$ \\
\hline & AOPP & $8.3 \pm 1.67$ & $91.7 \pm 1.67$ & $0.0 \pm 0.0$ & $2.0 \pm 0.19$ \\
\hline
\end{tabular}

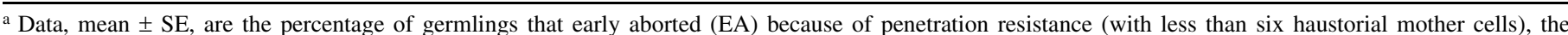
percentage of colonies that stopped development because of programmed cell death response, the percentage of established colonies without dead cells, and the colony size of established colonies.

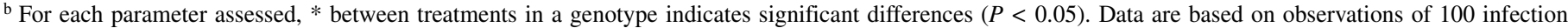
units per leaf with four different leaves assessed.

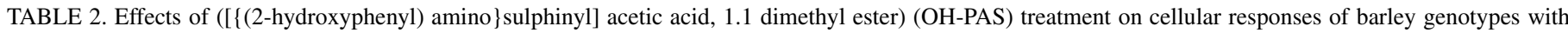
different forms of resistance to Puccinia hordei and in a nonhost interaction with wheat (cv. Little Club) at 3.5 days postinoculation ${ }^{\mathrm{a}}$

\begin{tabular}{|c|c|c|c|c|c|}
\hline Genotype & Treatment & $\begin{array}{c}\text { Penetration resistance }(\%) \\
\text { (EA colonies) }\end{array}$ & $\begin{array}{l}\text { Established colonies } \\
\text { with dead cells }(\%)\end{array}$ & $\begin{array}{l}\text { Established colonies } \\
\text { without dead cells }(\%)\end{array}$ & $\begin{array}{l}\text { Colony size } \\
\left(\mathrm{mm}^{2} \times 10^{-2}\right)\end{array}$ \\
\hline \multirow[t]{2}{*}{ L94 } & Control & $10.0 \pm 4.08$ & $2.5 \pm 1.20$ & $87.5 \pm 5.61$ & $31.6 \pm 12.50$ \\
\hline & OH-PAS & $4.7 \pm 1.45$ & $5.0 \pm 2.65$ & $90.3 \pm 3.53$ & $44.2 \pm 3.58$ \\
\hline \multirow[t]{2}{*}{ Vada } & Control & $59.3 \pm 3.55$ & $7.5 \pm 0.87$ & $33.2 \pm 2.93$ & $15.6 \pm 0.25$ \\
\hline & OH-PAS & $9.7 \pm 0.75^{* b}$ & $4.3 \pm 1.03$ & $86.0 \pm 1.58 *$ & $37.8 \pm 1.46 *$ \\
\hline \multirow[t]{2}{*}{17.5 .16} & Control & $45.7 \pm 4.03$ & $4.3 \pm 1.31$ & $50.0 \pm 4.98$ & $18.8 \pm 1.07$ \\
\hline & OH-PAS & $60.5 \pm 2.33^{*}$ & $2.3 \pm 1.03$ & $37.2 \pm 3.21 *$ & $15.8 \pm 0.25 *$ \\
\hline \multirow[t]{2}{*}{ Ribari (Rph3) } & Control & $16.3 \pm 1.80$ & $30.5 \pm 5.38$ & $53.2 \pm 3.90$ & $30.3 \pm 0.87$ \\
\hline & OH-PAS & $1.5 \pm 0.87 *$ & $3.5 \pm 1.44 *$ & $95.0 \pm 1.58 *$ & $53.5 \pm 1.45 *$ \\
\hline \multirow[t]{2}{*}{ L94+Rph7 } & Control & $5.8 \pm 1.49$ & $82.8 \pm 4.75$ & $11.4 \pm 3.52$ & $39.8 \pm 0.95$ \\
\hline & OH-PAS & $10.5 \pm 2.63$ & $68.8 \pm 7.89 *$ & $20.7 \pm 8.34$ & $35.6 \pm 2.61$ \\
\hline \multirow[t]{2}{*}{ Little Club } & Control & $7.2 \pm 2.70$ & $92.8 \pm 2.70$ & $0.0 \pm 0.0$ & $4.6 \pm 0.91$ \\
\hline & OH-PAS & $6.7 \pm 1.31$ & $93.3 \pm 1.31$ & $0.0 \pm 0.0$ & $2.4 \pm 1.16$ \\
\hline
\end{tabular}

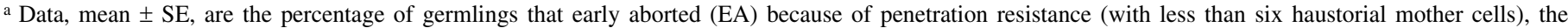
percentage of colonies that stopped development because of programmed cell death response, the percentage of established colonies without dead cells, and the colony size of established colonies.

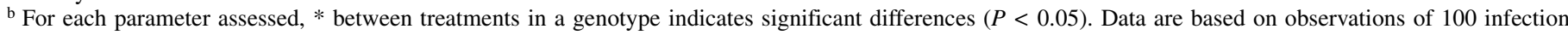
units per leaf with four different leaves assessed.

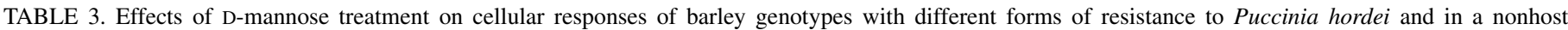
interaction with wheat (cv. Little Club) at 3.5 days postinoculation ${ }^{\mathrm{a}}$

\begin{tabular}{|c|c|c|c|c|c|}
\hline Genotype & Treatment & $\begin{array}{c}\% \text { Penetration resistance } \\
\text { (EA colonies) }\end{array}$ & $\begin{array}{c}\% \text { Established colonies } \\
\text { with dead cells }\end{array}$ & $\begin{array}{c}\% \text { Established colonies } \\
\text { without dead cells }\end{array}$ & $\begin{array}{l}\text { Colony size } \\
\left(\mathrm{mm}^{2} \times 10^{-2}\right)\end{array}$ \\
\hline \multirow[t]{2}{*}{ L94 } & Control & $3.8 \pm 0.56$ & $0.2 \pm 0.24$ & $96.0 \pm 0.28$ & $39.1 \pm 4.81$ \\
\hline & D-mannose & $2.8 \pm 0.92$ & $1.2 \pm 0.27$ & $96.0 \pm 0.57$ & $23.3 \pm 8.81$ \\
\hline \multirow[t]{2}{*}{ Vada } & Control & $16.8 \pm 1.50$ & $1.9 \pm 0.63$ & $81.3 \pm 1.83$ & $25.2 \pm 1.18$ \\
\hline & D-mannose & $2.0 \pm 0.07 * \mathrm{~b}$ & $2.0 \pm 0.48$ & $96.0 \pm 0.54$ & $27.8 \pm 2.60$ \\
\hline \multirow[t]{2}{*}{17.5 .16} & Control & $16.3 \pm 0.51$ & $1.0 \pm 1.08$ & $82.7 \pm 0.59$ & $24.3 \pm 1.57$ \\
\hline & D-mannose & $1.0 \pm 0.15^{*}$ & $1.0 \pm 0.99$ & $98.0 \pm 1.03$ & $27.1 \pm 4.38$ \\
\hline \multirow[t]{2}{*}{ Ribari (Rph3) } & Control & $10.0 \pm 3.24$ & $66.6 \pm 7.46$ & $23.4 \pm 6.57$ & $25.2 \pm 4.31$ \\
\hline & D-mannose & $4.4 \pm 2.19$ & $51.9 \pm 8.20$ & $43.7 \pm 10.25 *$ & $28.4 \pm 6.66$ \\
\hline \multirow{2}{*}{ L94+Rph7 } & Control & $0.6 \pm 0.16$ & $91.7 \pm 3.34$ & $7.7 \pm 3.11$ & $40.7 \pm 6.57$ \\
\hline & D-mannose & $0.6 \pm 0.21$ & $65.7 \pm 2.75^{*}$ & $33.7 \pm 3.58 *$ & $41.0 \pm 3.24$ \\
\hline \multirow[t]{2}{*}{ Little Club } & Control & $6.0 \pm 0.84$ & $92.5 \pm 1.72$ & $1.5 \pm 1.68$ & $0.6 \pm 0.60$ \\
\hline & D-mannose & $9.1 \pm 2.94$ & $23.4 \pm 5.60 *$ & $67.5 \pm 4.87 *$ & $1.6 \pm 0.30 *$ \\
\hline
\end{tabular}

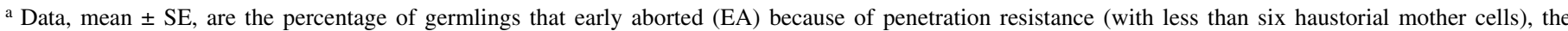
percentage of colonies that stopped development due to programmed cell death response, the percentage of established colonies without dead cells, and the colony size of established colonies.

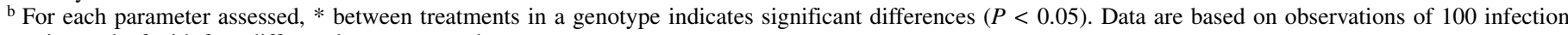
units per leaf with four different leaves assessed. 
the already small percentage of dead cells significantly. This was reflected in the small but significant increase of colony size after treatment (Table 1). PAL and CAD inhibitors also diminished the resistance of Ribari. In this case, the inhibitors reduced the penetration resistance and percentage of PCD and led to a significant increase in colony size, from approximately 0.3 to $0.5 \mathrm{~mm}^{2}$. In L94+Rph7, PAL inhibition had no effect on resistance (Table 1), but OH-PAS treatment decreased PCD (Table 2). Neither AOPP nor OH-PAS had any detectable effect in the nonhost interaction between wheat and P. hordei (Tables 1 and 2).

D-Mannose did not reduce the already low percentage of urediniospores (approximately 4\%) that successfully penetrated the mesophyll cells of the barley susceptible genotype L94 (Table 3). D-Mannose dramatically reduced the penetration resistance in Vada and 17.5.16. The percentage of urediniospores that failed penetration and aborted early in the infection process was reduced approximately $90 \%$ in both genotypes compared with their appropriate controls (Table 3). Following the D-mannose treatment, the genotype Ribari showed a slight but not significant decrease in penetration resistance. By contrast, D-mannose significantly reduced the percentage of cell death in L94+Rph7.

Interestingly, D-mannose strongly and significantly reduced the resistance in the nonhost interaction between the wheat genotype, Little Club, and P. hordei. Thus, cell death decreased from $92.5 \%$ in controls to $23.4 \%$ in D-mannose-treated leaves. This contributed to a significant increase in establishment of colonies and in colony size observed in this nonhost.

\section{DISCUSSION}

Effects of inhibitors on barley mesophyll cell resistance to $\boldsymbol{P}$. hordei. Penetration resistance. Penetration resistance associated with papilla deposition in mesophyll cells has been described in plant-rust interactions $(12,18)$. However, very few studies assessed the effect of phenylpropanoid inhibition in penetration resistance during cereal-rust interactions. Most studies of penetration resistance have been done in the cereal powdery mildew system. In these, suppression of PAL in oat, wheat, and barley reduced penetration resistance to appropriate $B$. graminis f. spp. $(2,4-6,16)$. This effect was correlated with a decrease in local accumulation of phenolics that strengthen the cell wall or act as fungitoxic compounds in papillae (16). In the current work, AOPP and $\mathrm{OH}-\mathrm{PAS}$ reduced the penetration resistance of Vada and Ribari barleys characterized with high or moderate penetration resistance. This suggests that phenylpropanoid derivatives, and specifically cinnamyl alcohols or related products of the lignin biosynthetic pathway, play an important role in penetration resistance in these genotypes. In a previous work, we reported the importance of a phenylpropanoid pathway in papilla formation of various faba bean genotypes against the faba bean rust (33). The current results in the cereal-rust interaction confirm the crucial role of these compounds achieving mesophyll penetration resistance in some but not all genotypes.

Conversely, neither AOPP nor OH-PAS treatments reduced the penetration resistance in the genotype 17.5.16. This suggests that although phenylpropanoid biosynthesis might be involved in papilla effectiveness, it is not a critical process in this barley genotype. On the other hand, penetration resistance of 17.5 .16 was almost completely abolished by D-mannose. In plants cells, Dmannose is rapidly phosphorylated by endogenous hexokinases to mannose-6-phosphate that is slowly if at all metabolized. Thus, Dmannose decreases the inorganic phosphate level available, resulting in a disruption of all energy-requiring reactions in the cell $(9,11,13,40)$. D-Mannose also interferes with many cell processes including sugar sensing (34), and importantly, early defense responses including protein kinase signaling cascades and production of phosphatase dependent transcription factors $(1,34)$. Interestingly, previous studies from the barley powdery mildew system showed that D-mannose suppressed the race nonspecific penetration resistance due to the mlo5 allele that otherwise led to a highly effective papilla-based resistance (17). There, phenolic biosynthesis inhibition had no effect on penetration resistance (41). The penetration resistance of 17.5.16 to its rust resembles the penetration resistance observed in mlo barley powdery mildew interaction where resistance does not seem to rely solely on phenylpropanoid biosynthesis (16). This is in agreement with a recent work in which we observed that high penetration resistance of a faba bean genotype to its rust could not be reduced by phenylpropanoid inhibition but was abolished by D-mannose and confirms the existence of differing mechanisms of penetration resistance against rust fungi (33).

PCD (hypersensitivity). PAL inhibitors suppressed resistance in several host-pathogen interactions in which resistance was race specific and expressed as PCD such as soybean-Phythophthora megasperma f. sp. glycinea (23), cowpea-Phythophthora vignae (31), barley and oat powdery mildew $(2,4-6,16,41)$, and wheatPuccinia graminis f. sp. tritici $(22,39)$. Here we assessed two genotypes with hypersensitive response, Ribari (Rph3) and L94+Rph7. In agreement with previous reports, treatment with AOPP and OH-PAS dramatically diminished PCD-based resistance of Ribari, but only OH-PAS slightly decreased resistance of L94+Rph7. In L94+Rph7, it may be that leaf rust led to a late phenolic accumulation that was insufficient to account for resistance, as was also described in the cowpea-cowpea rust fungus interaction (8). Indeed, in L94+Rph7, PCD was associated with large colonies similar to those of the susceptible control, indicating a late-induced cell death. Late PCD in Rph7 lines were previously described by Niks and Kuiper (27). By achieving a timecourse study of the infection process, they reported a late effect of $R p h 7$, contrasting with the early action of Rph3. Interestingly, Dmannose reduced the PCD of L94+Rph7, suggesting interference in kinase signaling cascades, production of phosphatase dependent transcription factors, or other energy-dependent processes $(1,34)$ crucial for PCD orchestration. Mannose also increased the percentage of established colonies without associated dead cells in Ribari. In this case, colony size increased slightly but increment was not significant. Fungitoxicity effects of some phosphate scavengers, such as DDG, have been previously reported (30). Although it has been reported that D-mannose is not as fungitoxic as is DDG (30), the low colony size increase in Ribari may have been because of a particularly high antifungal activity level in this cultivar, causing cessation of fungal development.

Effects of inhibitors on wheat mesophyll resistance to $P$. hordei. The nonhost interaction wheat- $P$. hordei was characterized by an extremely rapid PCD, resulting in very small colonies. There was no effect of phenylpropanoid pathway inhibitors, but there was a strong suppression of this early PCD following Dmannose treatment. This is in agreement with previous studies on appropriate and inappropriate interactions in the cereal powdery mildew fungus in which phenylpropanoid inhibitors had no effect but that D-manosse did have an effect $(5,43)$. Lack of effect of PAL inhibitors to induce susceptibility to nonpathogens was previously reported in wheat (32), and in pea, it was reported that phenolic compounds accumulate following infection, but accumulate too late to account for nonhost resistance (21).

Our results are consistent with Christopher-Kozjan and Heath (7) who reported distinct patterns in the cytology and timing of the cell death processes during the PCD triggered in host or nonhost interactions between cowpea and the cowpea rust fungus (Uromyces vignae) or the plantain powdery mildew (Erysiphe cichoracearum), respectively. In their system (7), cell death in nonhost interactions is completed in less than $1 \mathrm{~h}$. It is accompanied by Brownian-like motion of particulates in cytoplasm, movement of the host nucleus toward the intercellular fungus, and caspase activity. Conversely, in appropriate host interaction, PCD took at least $2 \mathrm{~h}$ and there was neither Brownian movement within 
the cytoplasm, movement of the host cell nucleus, nor caspase activity. Thus, in our experiments, D-mannose might inhibit energy required at very early stages in the nonhost interaction or interfere with crucial phosphate-dependent signaling or transcription processes. Indeed, during apoptosis in mammals, specific transcription factors need to be dephosphorylated for the subsequent cleavage by caspases leading to apoptosis (PCD) (15). Similar processes may well be necessary in plant PCD.

Altogether, our data sheds light on the physiological and molecular basis governing resistance mechanisms in cereal-rust appropriate and nonhost interactions. Interestingly, results suggest commonalities with the response of cereal epidermal cells attacked by powdery mildew regarding to penetration resistance, PCD, and nonhost resistance mechanisms that might be useful for finding plants with resistance to both biotrophic pathogens.

\section{ACKNOWLEDGMENTS}

We gratefully acknowledge CYCIT projects AGF99-1036 and AGL2005-01781 and MERG 013083 for financial support.

\section{LITERATURE CITED}

1. Carrasco, J. L., Ancillo, G., Mayda, E., and Vera, P. 2003. A novel transcription factor involved in plant defense endowed with protein phosphatase activity. EMBO J. 22:3376-3384.

2. Carver, T. L. W., Robbins, M. P., and Zeyen, R. J. 1991. Effects of 2 PAL inhibitors on the susceptibility and localized autofluorescent host-cell responses of oat leaves attacked by Erysiphe graminis DC. Physiol. Mol. Plant Pathol. 39:269-287.

3. Carver, T. L. W., and Zeyen, R. J. 1993. Effects of PAL and CAD inhibition on powdery mildew resistance phenomena in cereals. Pages 324-327 in: Mechanisms of plant defense responses. B. Fritig and M. Legrand, eds. Kluwer Academic Publisher. Dordrecht, the Netherlands.

4. Carver, T. L. W., Zeyen, R. J., Bushnell, W. R., and Robbins, M. P. 1994. Inhibition of phenylalanine ammonia-lyase and cinnamyl alcohol-dehydrogenase increases quantitative susceptibility of barley to powdery mildew (Erysiphe graminis DC). Physiol. Mol. Plant Pathol. 44:261-272.

5. Carver, T. L. W., Zeyen, R. J., Robbins, M. P., and Dearne, G. A. 1992. Effects of the PAL inhibitor, AOPP, on oat, barley and wheat cell responses to appropriate and inappropriate formae specialis of Erysiphe graminis DC. Physiol. Mol. Plant Pathol. 41:397-409.

6. Carver, T. L. W., Zeyen, R. J., Robbins, M. P., Vance, C. P., and Boyles, D. A. 1994. Suppression of host cinnamyl alcohol-dehydrogenase and phenylalanine ammonia-lyase increases oat epidermal-cell susceptibility to powdery mildew penetration. Physiol. Mol. Plant Pathol. 44:243259.

7. Christopher-Kozjan, R., and Heath, M. C. 2003. Cytological and pharmacological evidence that biotrophic fungi trigger different cell death execution processes in host and nonhost cells during the hypersensitive response. Physiol. Mol. Plant Pathol. 62:265-275.

8. Fink, W., Haug, M., Deising, H., and Mendgen, K. 1991. Early defense responses of cowpea (Vigna sinensis L.) induced by nonpathogenic rust fungi. Planta 185:246-254.

9. Harris, G. C., Gibbs, P. A., Ludwig, G., Un, A., and Sprengnether, M. N. 1986. Mannose metabolism in corn and its impact on leaf metabolites, photosynthetic gas exchange, and chlorophyll fluorescence. Plant Physiol. 82:1081-1089.

10. Heath, M. C. 2000. Hypersensitive response-related death. Plant Mol. Biol. 44:321-334.

11. Herold, A., and Lewis, D. H. 1977. Mannose and green plants: Occurrence, physiology and metabolism, and use as a tool to study the role of orthophosphate. New Phytol. 79:1-40.

12. Jacobs, T. 1989. The occurrence of cell-wall appositions in flag leaves of spring wheats, susceptible and partially resistant to wheat leaf rust. J. Phytopathol. 127:239-249.

13. Joersbo, M., Donaldson, I., Kreiberg, J., Petersen, S. G., Brunstedt, J., and Okkels, F. T. 1998. Analysis of mannose selection used for transformation of sugar beet. Mol. Breed. 4:111-117.

14. Kang, Z., Huang, L. L., and Buchenauer, H. 2002. Ultrastructural changes and localization of lignin and callose in compatible and incompatible interactions between wheat and Puccinia striiformis. J. Plant Dis. Prot. 109:25-37.

15. Krippner-Heidenreich, A., Talanian, R. V., Sekul, R., Kraft, R., Thole, H., Ottleben, H., and Luscher, B. 2001. Targeting of the transcription factor Max during apoptosis: Phosphorylation-regulated cleavage by caspase- 5 at an unusual glutamic acid residue in position P1. Biochem. J. 358:705715 .

16. Kruger, W. M., Carver, T. L. W., and Zeyen, R. J. 2002. Effects of inhibiting phenolic biosynthesis on penetration resistance of barley isolines containing seven powdery mildew resistance genes or alleles. Physiol. Mol. Plant Pathol. 61:41-51.

17. Lyngkjaer, M. F., Carver, T. L. W., and Zeyen, R. J. 1997. Suppression of resistance to Erysiphe graminis f. sp. hordei conferred by the mlo5 barley powdery mildew resistance gene. Physiol. Mol. Plant Pathol. 50:17-36.

18. Ma, Q., and Shang, H. S. 2004. Ultrastructural analysis of the interaction between Puccina striiformis f. sp. tritici and wheat after thermal induction of resistance. J. Plant Pathol. 86:19-26.

19. Martínez, F., Niks, R. E., and Rubiales, D. 2001. Partial resistance to leaf rust in a collection of ancient Spanish barleys. Hereditas 135:199-203.

20. Martínez, F., Sillero, J. C., and Rubiales, D. 2004. Effect of host plant resistance on haustorium formation in cereal rust fungi. J. Phytopathol. 152:381-382.

21. Mellersh, D. G., Foulds, I. V., Higgins, V. J., and Heath, M. C. 2002. $\mathrm{H}_{2} \mathrm{O}_{2}$ plays different roles in determining penetration failure in three diverse plant-fungal interactions. Plant J. 29:257-268.

22. Moerschbacher, B. M., Noll, U., Ocampo, C. A., Flott, B. E., Gotthardt, U., Wüstefeld, A., and Reisener, H. J. 1990. Hypersensitive lignification response as the mechanism of non-host resistance of wheat against oat crown rust. Physiol. Plant. 78:609-615.

23. Moesta, P., and Grisebach, H. 1982. L-2-Aminooxy-3-Phenylpropionic acid inhibits phytoalexin accumulation in soybean with concomitant loss of resistance against Phytophthora megasperma f. sp glycinea. Physiol. Plant Pathol. 21:65-70.

24. Niks, R. E. 1982. Early abortion of colonies of leaf rust, Puccinia hordei, in partially resistant barley seedlings. Can J. Bot. 60:714-723.

25. Niks, R. E. 1986. Failure of haustorial development as a factor in slow growth and development of Puccinia hordei in partially resistant barley seedlings. Physiol. Mol. Plant Pathol. 28:309-322.

26. Niks, R. E., and Dekens, R. G. 1991. Prehaustorial and posthaustorial resistance to wheat leaf rust in diploid wheat seedlings. Phytopathology 81:847-851

27. Niks, R. E., and Kuiper, H. J. 1983. Histology of the relation between minor and mayor genes for resistance of barley to leaf rust. Phytopathology 73:55-59.

28. Niks, R. E., and Rubiales, D. 1994. Avirulence factors corresponding to barley genes $\mathrm{Pa} 3$ and $\mathrm{Pa} 7$ which confer resistance against Puccinia hordei in rust fungi other than $P$. hordei. Physiol. Mol. Plant Pathol. 45:321331.

29. Parlevliet, J. E., and Kievit, C. 1986. Development of barley leaf rust, Puccinia hordei, infections in barley.1. Effect of partial resistance and plant stage. Euphytica 35:953-959.

30. Prats, E., Carver, T. L. W., Lyngkjaer, M. F., Roberts, P. C., Zeyen, R. 2006. Induced inaccessibility and accessibility in the oat powdery mildew system: Insights gained from use of metabolic inhibitors and silicon nutrition. Mol. Plant Pathol. 7:47-59.

31. Ralton, J. E., Howlett, B. J., Clarke, A. E., Irwin, J. A. G., and Imrie, B. 1988. Interaction of cowpea with Phytophthora vignae - Inheritance of resistance and production of phenylalanine ammonia-lyase as a resistance response. Physiol. Mol. Plant Pathol. 32:89-103.

32. Ride, J. P., and Barber, M. S. 1987. The effects of various treatments on induced lignification and the resistance of wheat to fungi. Physiol. Mol. Plant Pathol. 31:349-360.

33. Rojas-Molina, M. D., Rubiales, D., Prats, E., and Sillero, J. C. 2007. Effects of phenylpropanoid and energetic metabolism inhibition on faba bean resistance mechanisms to rust. Phytopathology 97:60-65.

34. Rolland, F., Moore, B., and Sheen, J. 2002. Sugar sensing and signaling in plants. Plant Cell 14:S185-S205.

35. Skalamera, D., and Heath, M. C. 1995. Changes in the plant endomembrane system associated with callose synthesis during the interaction between cowpea (Vigna unguiculata) and the cowpea rust fungus (Uromyces vignae). Can J. Bot. 73:1731-1738.

36. Skalamera, D., and Heath, M. C. 1996. Cellular mechanisms of callose deposition in response to fungal infection or chemical damage. Can. J. Bot. 74:1236-1242.

37. Southerton, S. G., and Deverall, B. J. 1990. Histochemical and chemical evidence for lignin accumulation during the expression of resistance to leaf rust fungi in wheat. Physiol. Mol. Plant Pathol. 36:483-494.

38. Southerton, S. G., and Deverall, B. J. 1990. Changes in phenylalanine ammonia-lyase and peroxidase-activities in wheat cultivars expressing resistance to the leaf-rust fungus. Plant Pathol. 39:223-230.

39. Tiburzy, R., and Reisener, H. J. 1990. Resistance of wheat to Puccinia graminis f. sp. tritici association of the hypersensitive reaction with the cellular accumulation of lignin-like material and callose. Physiol. Mol. Plant Pathol. 36:109-120. 
40. Weiner, H., McMichael, R. W., and Huber, S. C. 1992. Identification of factors regulating the phosphorylation status of sucrose-phosphate synthase in vivo. Plant Physiol. 99:1435-1442.

41. Zeyen, R. J., Bushnell, W. R., Carver, T. L. W., Robbins, M. P., Clark, T. A., Boyles, D. A., and Vance, C. P. 1995. Inhibiting phenylalanine ammonia-lyase and cinnamyl-alcohol dehydrogenase suppresses Mlal (HR) but not Mlo5 (non-HR) barley powdery mildew resistances. Physiol. Mol. Plant Pathol. 47:119-140.
42. Zeyen, R. J., Carver, T. L. W., and Lyngkjaer, M. F. 2002. Epidermal cell papillae. Pages 107-125 in: Powdery Mildews: A Comprehensive Treatise. R. R. Belanger, W. R. Bushnell, A. J. Dik, and T. L. W. Carver, eds. American Phytopathological Society, St. Paul, MN.

43. Zeyen, R. J., Kruger, W. M., Lyngkjær, M. F., and Carver, T. L. W. 2002. Differential effects of D-mannose and 2-deoxy-D-glucose on attempted powdery mildew fungal infection of inappropriate and appropriate Gramineae. Physiol. Mol. Plant Pathol. 61:315-323. 